\title{
Tensile Properties of TiAl Based Alloy in a Gaseous Hydrogen Atmosphere in a Temperature Range from Room Temperature to $973 \mathrm{~K}$
}

\author{
Morihiko NAKAMURA, Eiji ABE, Kewei GAO, ${ }^{1)}$ Lijie OIAO ${ }^{1)}$ and Wuyang $\mathrm{CHU}^{11}$ \\ National Institute for Materials Science, Sengen, Tsukuba-shi, Ibaraki 305-0053 Japan. \\ 1) University of Science and Technology Beijing, Beijing 100083, China.
}

(Received on August 31, 2002; accepted in final form on November 5, 2002)

\begin{abstract}
$\mathrm{Ti}-48 \mathrm{Al}-2 \mathrm{Cr}-2 \mathrm{Nb}$ (at\%) with a $\gamma$ phase structure was tensile-tested in a high purity hydrogen gas in a temperature range of room temperature to $973 \mathrm{~K}$. The reduction of elongation was observed in hydrogen gas in the entire temperature range, although the fracture surface changed mainly from cleavage to grain boundary facets both in vacuum and in hydrogen gas as the temperature increases. From transmission electron microscopy, fractography, the content of hydrogen introduced during tensile testing, and consideration of the diffusion rate of hydrogen, the hydrogen environmental embrittlement of the TiAl based alloy is suggested to result not from the formation of hydrides but from local accumulation of solute hydrogen introduced by dislocations from the test environment during testing. The hydrogen introduced during tensile deformation mainly decreases not grain boundary strength but cleavage strength, and then the reduction of elongation in hydrogen gas is caused by the decrease of the transgranular strength in the wide temperature range, although the grain boundary strength may also decrease with increasing temperature.
\end{abstract}

KEY WORDS: TiAl based alloy; hydrogen gas; environmental embrittlement; tensile property; elevated temperature.

\section{Introduction}

TiAl-based alloys have shown great potential for application in aerospace industry, due to their low density and good high-temperature properties. Since future aircrafts are expected to be fueled by hydrogen, it is required to understand the interaction between TiAl based alloys and hydrogen, especially the mechanical properties in a gaseous hydrogen atmosphere in a wide temperature range.

The strength of TiAl based alloys decreases rapidly with increasing temperature above $1073 \mathrm{~K},{ }^{1)}$ and the hydrogen propulsion system for aircrafts requires working temperatures below $923 \mathrm{~K}$ in hydrogen-rich steam. ${ }^{2)}$ Thus, it is essential that the mechanical properties of TiAl-based alloys are examined in a hydrogen gas at temperatures below $923 \mathrm{~K}$.

Environmental embrittlement at room temperature has been investigated so far for various intermetallic compounds. $\mathrm{Ni}_{3} \mathrm{Al}^{3,}{ }^{3,4)} \mathrm{Co}_{3} \mathrm{Ti}^{5},{ }^{5)} \mathrm{Ni}_{3} \mathrm{Si}^{6},{ }^{6}(\mathrm{Co}, \mathrm{Fe})_{3} \mathrm{~V}^{7)}$ and $\mathrm{Fe}-\mathrm{Al}^{8)}$ based intermetallic alloys have been reported to exhibit the environmental embrittlement in laboratory air and in a hydrogen gas, that is, their tensile elongation in these environments is decreased, compared with that in vacuum or oxygen gas. The environmental embrittlement of these intermetallic compounds is caused by hydrogen which is produced through reaction of the material surface with moisture in air $^{9)}$ or hydrogen gas.

TiAl based alloys also exhibit environmental embrittlement in laboratory air and hydrogen gas at room tempera- ture, ${ }^{10,11)}$ and the microstructure of the alloys affects the environmental embrittlement at room temperature. ${ }^{12}$ Furthermore TiAl based alloys exhibit the reduction of elongation in a hydrogen gas not only at room temperature but also at $573 \mathrm{~K}^{13)}$

The environmental embrittlement of intermetallic compounds have hardly been investigated at elevated temperatures, although $\mathrm{L}_{2}$ type intermetallic alloys such as $\mathrm{Ni}_{3} \mathrm{Si}$ and $\mathrm{Ni}_{3} \mathrm{Al}$ based alloys are reported to exhibit smaller elongation in air than in vacuum at elevated temperatures. ${ }^{14,15)}$ The reduction of elongation in air at elevated temperatures is considered to be caused by oxygen. Meanwhile, it is reported that steels which were cathodically charged with hydrogen exhibited no embrittlement at temperatures as low as $77 \mathrm{~K}$ and as high as $400 \mathrm{~K}$, although they exhibited considerable embrittlement near room temperature. ${ }^{16)}$

The purpose of this work is to examine hydrogen environmental embrittlement in a wide temperature range of room temperature to $973 \mathrm{~K}$ for a TiAl based alloy. Then it is discussed what causes hydrogen environmental embrittlement of a TiAl based alloy, based on transmission electron microscopic observation, fractography, and the consideration of the diffusion rate and the content of hydrogen in specimens tested in hydrogen gas.

\section{Experimental Procedure}

The alloy used was $\mathrm{Ti}-48 \mathrm{Al}-2 \mathrm{Cr}-2 \mathrm{Nb}$ (at $\%$ ) and the chemical compositions denoted with wt $\%$ were as follows. 


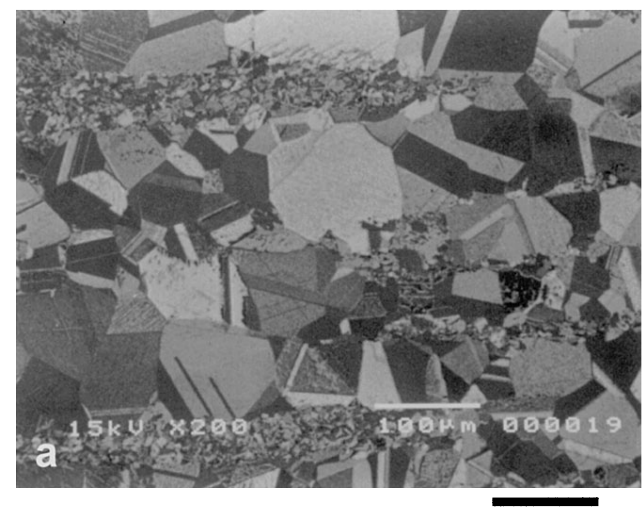

$100 \mu \mathrm{m}$

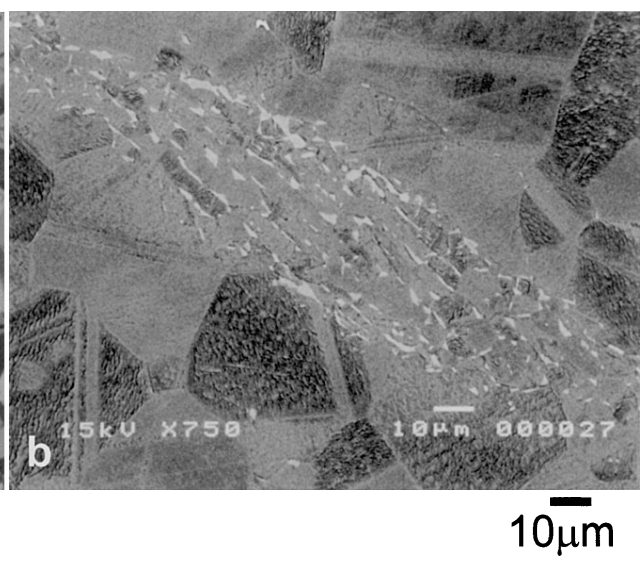

Fig. 1. Microstructure of the alloy heat-treated at $1313 \mathrm{~K}$. (a) Secondary electron image. (b) Backscattered electron image.

Al: 33.52 (48.2 at\%), Nb: 4.71 (1.97 at\%), Cr: $2.71(2.02$ at\%), Si: 0.007, Mn: <0.005, Fe: 0.10, Ni: 0.02, Cu: $<0.005$, C: 0.008, O: 0.063, N: 0.0041, H: 0.0009, Ti: bal. The alloy ingot of about $20 \mathrm{~kg}$ was prepared by inductionskull-melting in an argon atmosphere, and then the alloy bars of $16 \mathrm{~mm}$ in diameter were prepared by hot extrusion at $1473 \mathrm{~K}$. The extrusion ratio was 7.2.

Tensile specimens with a gage length of $15 \mathrm{~mm}$ and a gage section of $1.5 \times 4 \mathrm{~mm}$ were machined using an electric discharging machine (EDM). The tensile direction of the specimens was parallel to the longitudinal direction of the extruded bar. After mechanical polishing, they were heat treated at $1313 \mathrm{~K}$ for $50 \mathrm{~h}$ in an argon atmosphere in order to obtain a $\gamma$-single phase structure. After mechanical polishing followed by electro-polishing, the specimens were tensile-tested in a temperature range of room temperature to $973 \mathrm{~K}$ using a screw-driven testing machine at a constant crosshead speed of $0.2 \mathrm{~mm} / \mathrm{min}$ (a nominal strain rate of $\left.2 \times 10^{-4} \mathrm{~s}^{-1}\right)$. The test environments were vacuum $\left(<4 \times 10^{-4} \mathrm{~Pa}\right)$ and a flowing high purity hydrogen gas $(99.99999 \%)$ of $1 \mathrm{~atm}$. The test chamber, which was attached to the testing machine, was evacuated to better vacuum than $4 \times 10^{-4} \mathrm{~Pa}$, and then backfilled with the high purity hydrogen gas. This process was repeated four times, before the specimens were tested in the flowing hydrogen gas. The tensile tests were carried out after the specimens were heated to a given temperature followed by holding for $15 \mathrm{~min}$ in each environment. In most cases, three specimens were tested in each condition, and the average values were used for the tensile properties.

The fracture surfaces and microstructures of the specimens were observed using scanning electron microscopy (SEM) and transmission electron microscopy (TEM). After testing in the hydrogen gas, the hydrogen content of the specimens was measured using a gas-chromatographic method for samples melted in an inert gas (JIS H 1619). The samples were cut from the gage section of the specimens fractured in the hydrogen gas at various temperatures.

\section{Experimental Results}

Figure 1 shows the microstructure of the alloy heat-treated at $1313 \mathrm{~K}$. The secondary electron image shows that the alloy has an equiaxed grain structure with bands consisting

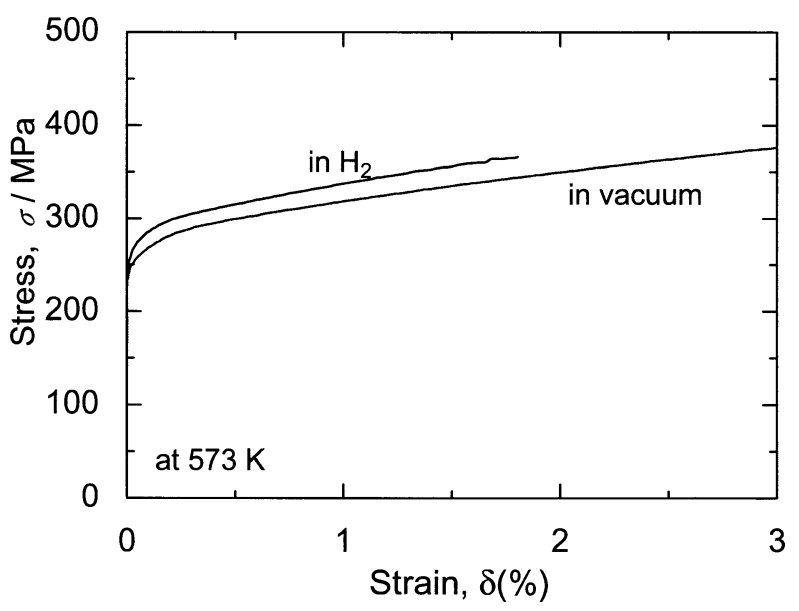

Fig. 2. Stress $v s$. plastic strain curves in vacuum and in hydrogen gas at $573 \mathrm{~K}$.

of small grains in the longitudinal direction of the alloy bar, and the backscattered electron image shows that it mainly consists of $\gamma$ grains with just a few amounts of small $\alpha_{2}$ grains.

Figure 2 shows examples of the stress $v s$. plastic strain curves at $573 \mathrm{~K}$ in vacuum and in hydrogen gas. In general, the flow stress is higher in hydrogen gas than in vacuum. The work-hardening rate at a small strain is higher in hydrogen than in vacuum, and the reduction of elongation is also observed in hydrogen gas. Figure 3 shows examples of the stress $v s$. plastic strain curves in hydrogen gas in the temperature range of room temperature to $973 \mathrm{~K}$. At room temperature, the flow stress is higher than at the other temperatures. $0.2 \%$ offset stress is similar in the temperature range of 573 to $973 \mathrm{~K}$, but a little difference in the flow stress is observed in this temperature range.

Figure 4 shows the temperature dependence of $0.2 \%$ offset stress in vacuum and in hydrogen gas. $0.2 \%$ offset stress in hydrogen gas is approximately equal to that in vacuum at each temperature, although it tends to be just a little higher in hydrogen gas than in vacuum. It exhibits a little decrease at $573 \mathrm{~K}$ and no change with temperature above this temperature. That is, this alloy does not exhibit a positive temperature dependence of $0.2 \%$ offset stress, which was observed for TiAl single crystals. ${ }^{17)}$ Figure 5 shows the temperature dependence of work-hardening rate at $1 \%$ 


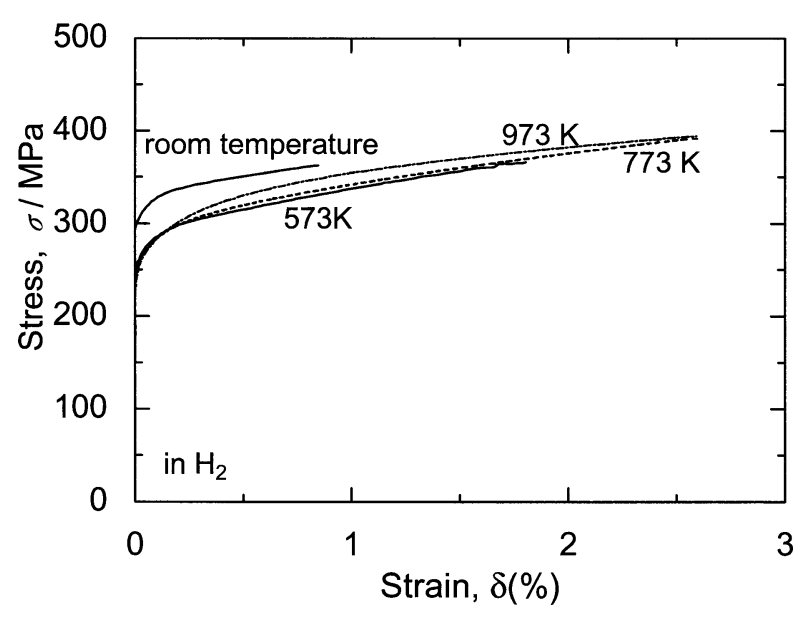

Fig. 3. Stress $v s$. plastic strain curves in hydrogen gas at various temperatures.

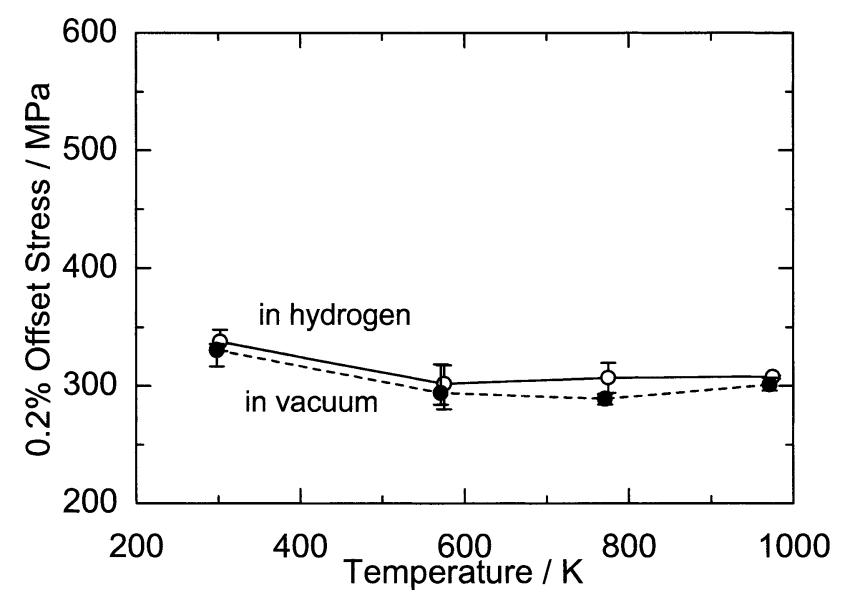

Fig. 4. Temperature dependence of $0.2 \%$ offset stress in vacuum and in hydrogen gas.

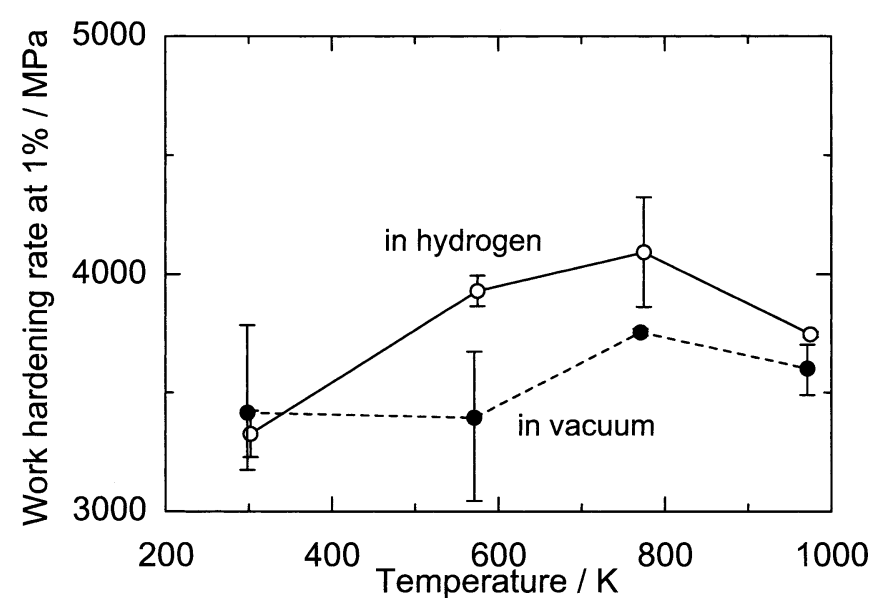

Fig. 5. Temperature dependence of work-hardening rate in vacuum and in hydrogen gas.

plastic strain in vacuum and in hydrogen gas. At room temperature, it exhibits no change with environments, but at the other temperatures, it is higher in hydrogen gas than in vacuum. In other words, in the early stage of plastic deformation, the hydrogen which is introduced from the hydrogen atmosphere hardly affects the plastic deformation at room temperature, but it affects the plastic deformation at the other temperatures. This fact may suggest that the diffu-

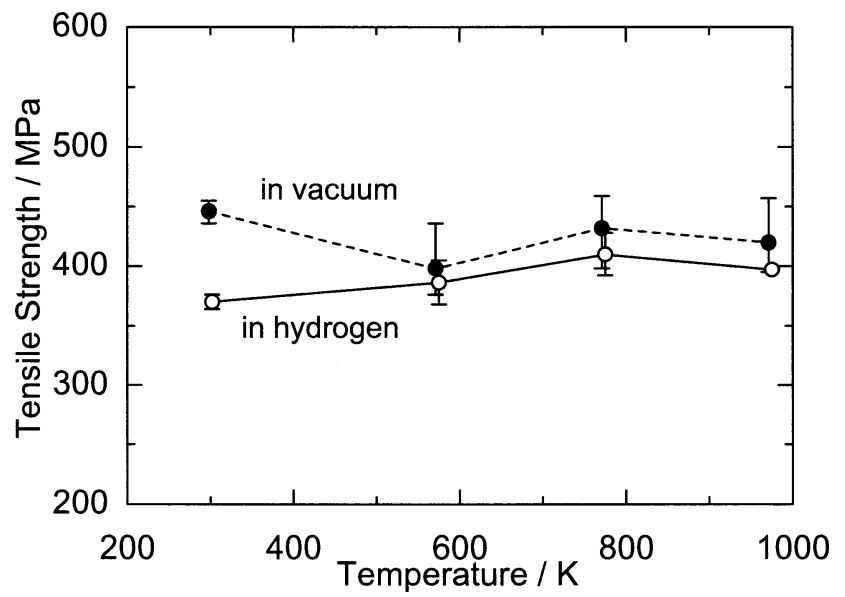

Fig. 6. Temperature dependence of tensile strength in vacuum and in hydrogen gas.

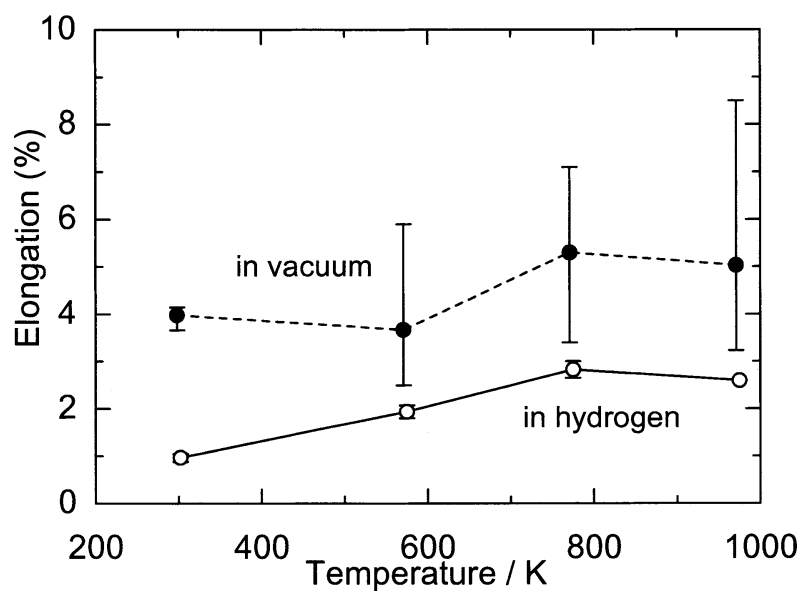

Fig. 7. Temperature dependence of elongation in vacuum and in hydrogen gas.

sion coefficient of hydrogen in TiAl based alloys is related to the dislocation motion. That is, the diffusion coefficient of hydrogen at room temperature is so low that hydrogen cannot interact with moving dislocations in the early stage of plastic deformation. The mobility of hydrogen increases with increasing temperature, and thus, at the higher temperatures the hydrogen atmosphere, which is formed near dislocations by the diffusive motion of hydrogen, may affect the plastic deformation. At a temperature as high as $973 \mathrm{~K}$, the diffusion coefficient of hydrogen increases further, and hydrogen has a tendency to move independently of the dislocation motion. This may be the reason why the difference in the work-hardening rate decreases at $973 \mathrm{~K}$.

Figure 6 shows the temperature dependence of tensile strength in vacuum and in hydrogen gas. At room temperature, the tensile strength is higher in vacuum than in hydrogen gas, but at temperatures of 573 to $973 \mathrm{~K}$, it is similar in both environments, although it is a little higher in vacuum. Thus, if the degree of hydrogen environmental embrittlement is evaluated from tensile strength, it may be concluded from Fig. 6 that the alloy is hardly embrittled in the hydrogen environment at temperatures above $573 \mathrm{~K}$.

Figure 7 shows the temperature dependence of elongation in vacuum and in hydrogen gas. The reduction of elongation is observed in hydrogen gas in the temperature range of room temperature to $973 \mathrm{~K}$, although the elongation is 

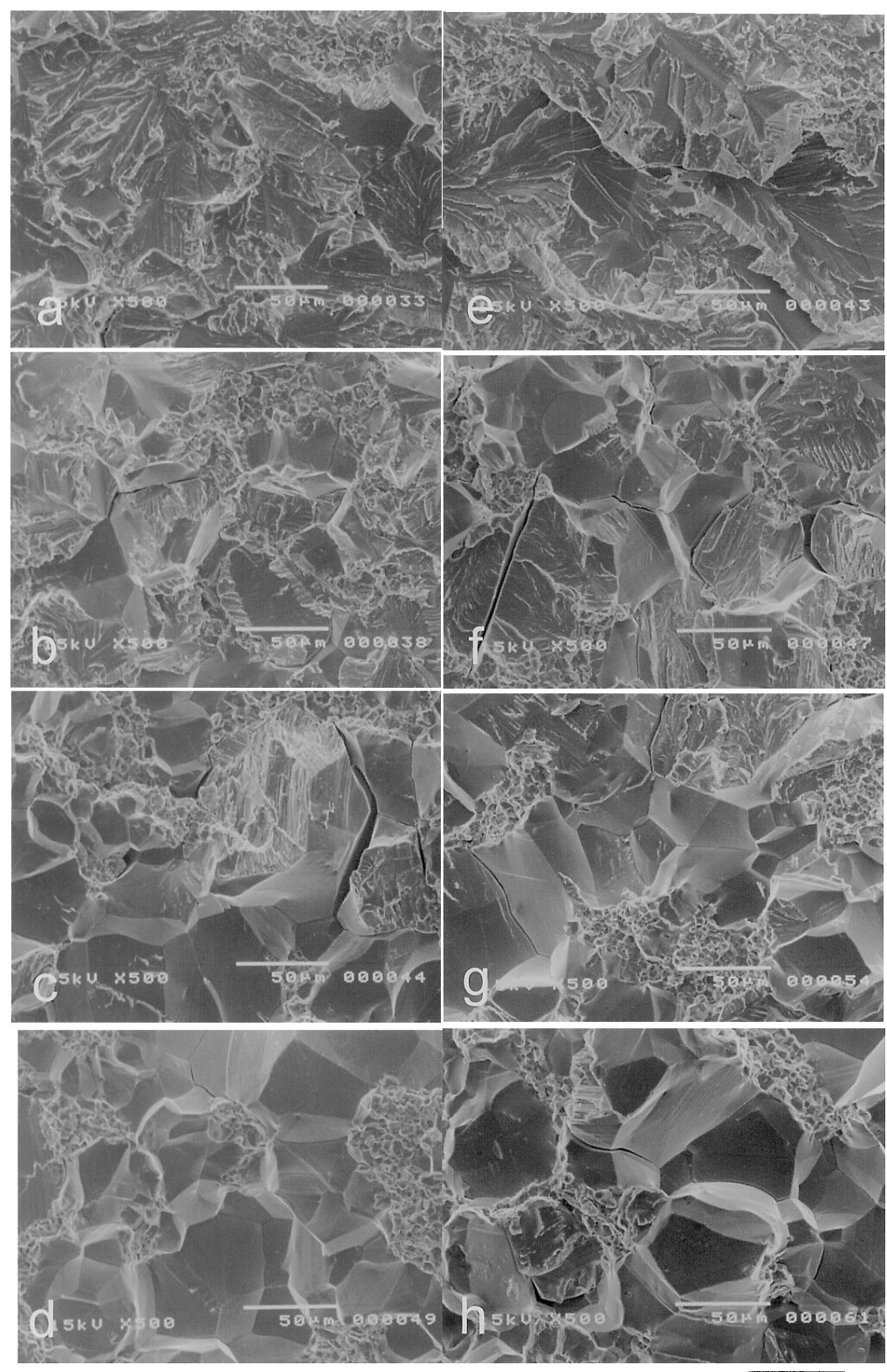

\section{$\overline{50 \mu \mathrm{m}}$}

Fig. 8. Fracture surfaces of specimens tested in vacuum at (a) room temperature, (b) $573 \mathrm{~K}$, (c) $773 \mathrm{~K}$ and (d) $973 \mathrm{~K}$, and in hydrogen gas at (e) room temperature, (f) $573 \mathrm{~K}$, (g) $773 \mathrm{~K}$ and (h) $973 \mathrm{~K}$.

increased at higher temperatures in hydrogen gas as well as in vacuum. That is, the hydrogen environmental embrittlement of the TiAl based alloy is observed even at a temperature as high as $973 \mathrm{~K}$. The amount of scattering in the measured elongation values is smaller in hydrogen gas, compared with that in vacuum. This is probably because the accumulation of hydrogen, which is introduced from the environment during tensile testing, is considered mainly to cause the fracture of the specimen, although the fracture of the specimen may also be affected by defects and/or flaws contained in the specimen. Meanwhile, the large amount of scattering in elongation is expected in vacuum, because the fracture in vacuum is mainly determined by defects and/or flaws, which distribute at random in the specimen.

Figure 8 shows the fractography near the surfaces of specimens tested at various temperatures in hydrogen gas and in vacuum, because the fracture in hydrogen is considered to initiate near the specimen surface, which may con- tain a large amount of hydrogen locally. No initiation site of the fracture could be observed at each temperature in hydrogen. This observation suggests that the fracture does not initiate at a specific site like hydride and inclusion even in hydrogen gas. The difference in fracture surfaces between the specimens tested in vacuum and in hydrogen is hardly observed at each temperature. At room temperature, the fracture surface consists mainly of cleavage facets. The grain boundary facets mixed with cleavage facets increase gradually with increasing test temperature. At $973 \mathrm{~K}$, just a few amounts of cleavage facets mixed with grain boundary facets are observed for the specimens tested both in hydrogen gas and in vacuum. These observations probably indicate that the hydrogen embrittlement of the TiAl alloy is caused by lowering of the cleavage fracture strength rather than the grain boundary strength even at higher temperature as well as at room temperature, ${ }^{10)}$ although the grain boundary strength may also decrease with increasing temperature. 


\section{Discussion}

The experimental results have clarified that TiAl exhibits hydrogen environmental embrittlement in a temperature range of room temperature to $973 \mathrm{~K}$. At room temperature, the embrittlement of the alloy is caused by hydrogen introduced through the fresh surface of the specimen, which is formed during plastic deformation in a hydrogen gas. ${ }^{18)}$ The hydrogen is considered mainly to be introduced by dislocations into the specimen and locally to accumulate at obstacles like grain boundaries, phase boundaries, etc. Here, the hydrogen environmental embrittlement of TiAl is discussed in a temperature range of room temperature to $973 \mathrm{~K}$.

The content of hydrogen in the specimens which had been tensile-tested in hydrogen gas was measured using gas-chromatography for the samples melted in an inert gas. The samples were mainly prepared from the gage section of the tensile specimens. Table 1 shows the hydrogen content of the specimens tested in the temperature range of room temperature to $973 \mathrm{~K}$. Compared with the hydrogen content for the cast alloy and the specimen tested in vacuum, the content is not increased by tensile deformation in hydrogen gas below $773 \mathrm{~K}$. It is increased by deformation at $973 \mathrm{~K}$, and is larger than the hydrogen content of the undeformed part of the specimen tested at $973 \mathrm{~K}$. Table 1 indicates that the reduction of elongation in hydrogen gas is caused by just a little amount of hydrogen introduced by deformation at temperatures of room temperature to $773 \mathrm{~K}$. Thus, the local accumulation of solute hydrogen introduced by dislocations through the fresh surface from the test environment is considered to cause the reduction of elongation.

Since the diffusive motion of hydrogen is more active at elevated temperatures than at room temperature, a relatively large amount of hydrogen is introduced into the specimen (see Table 1), and it is expected that hydrides, which result in the reduction of elongation, i.e. hydrogen embrittlement, are possible to be formed in the interior of the specimen. Thus, the microstructure of the specimens tested in hydrogen gas and in vacuum at $973 \mathrm{~K}$ was observed using transmission electron microscopy. Figure 9 shows the transmission electron micrography of the specimens fractured in hydrogen gas (a) and in vacuum (b) at $973 \mathrm{~K}$. The specimens were deformed in tension to the plastic strain of $2.6 \%$ in hydrogen gas and $3.4 \%$ in vacuum before fracture. Many mechanical twins are observed for both the specimens deformed in hydrogen gas and in vacuum, and this alloy is found to deform mainly by mechanical twins at $973 \mathrm{~K}$. No phases except for the $\gamma$ and $\alpha_{2}$ phases were observed for the specimen deformed in hydrogen gas as well as that deformed in vacuum. Figure $\mathbf{1 0}$ shows the diffraction pattern of Fig. 9(a). The diffraction pattern also shows no amorphous regions at the interface between the $\gamma$ and $\alpha_{2}$ phases. The amorphous regions were observed in the $\alpha_{2}$ phase for the fine $\gamma / \alpha_{2}$ lamella interface of the laths in Ti$49 \mathrm{at} \% \mathrm{Al} .{ }^{19)}$ No hydrides were also observed in the interior and grain boundaries of the $\gamma$ grains for the undeformed part, i.e. grip of the tensile specimen which was deformed in hydrogen gas at $973 \mathrm{~K}$ (Fig. 11). No hydrides are also reported for $\mathrm{Ti}-49 \mathrm{at} \% \mathrm{Al}$ containing about $0.02 \mathrm{wt} \% \mathrm{H}$, which was exposed to a hydrogen gas for $3 \mathrm{~h}$ at $1073 \mathrm{~K} .{ }^{19)}$ These observations as well as the fracture surface observation
Table 1. Hydrogen content for specimens tested in a temperature range of room temperature to $973 \mathrm{~K}$.

\begin{tabular}{lc}
\hline \multicolumn{1}{c}{ specimen } & hydrogen content $(\mathrm{wt} \%)$ \\
\hline in vacuum at R.T.\#1 & 0.0008 \\
in hydrogen gas at R.T.\#1 & 0.0006 \\
in hydrogen gas at $573 \mathrm{~K}$ & 0.0006 \\
in hydrogen gas at $773 \mathrm{~K}$ & 0.0009 \\
in hydrogen gas at $973 \mathrm{~K}$ & 0.0085 \\
in hydrogen gas at $973 \mathrm{~K} \# 2$ & 0.0068 \\
\hline
\end{tabular}

\#1: room temperature

\#2: undeformed part of specimen
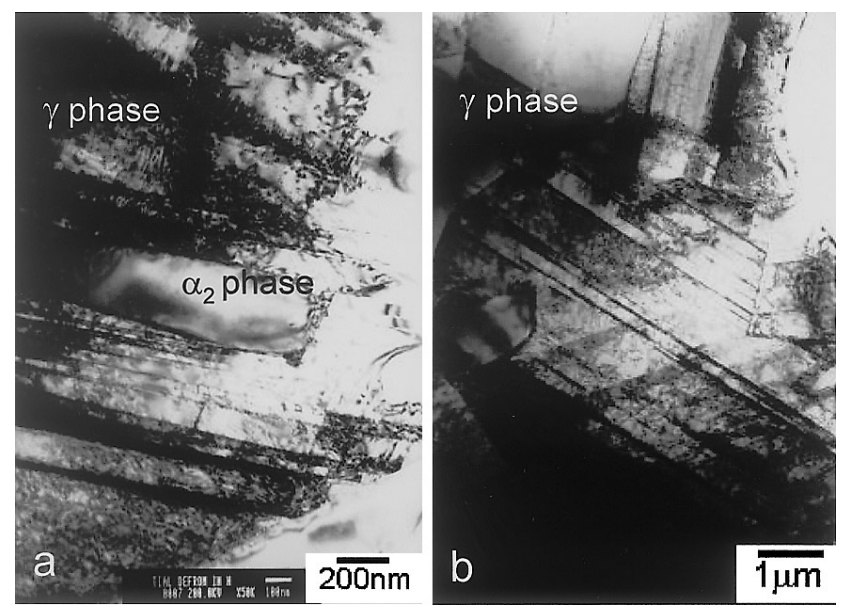

Fig. 9. TEM observation of specimens tested in hydrogen gas (a) and in vacuum (b) at $973 \mathrm{~K}$.

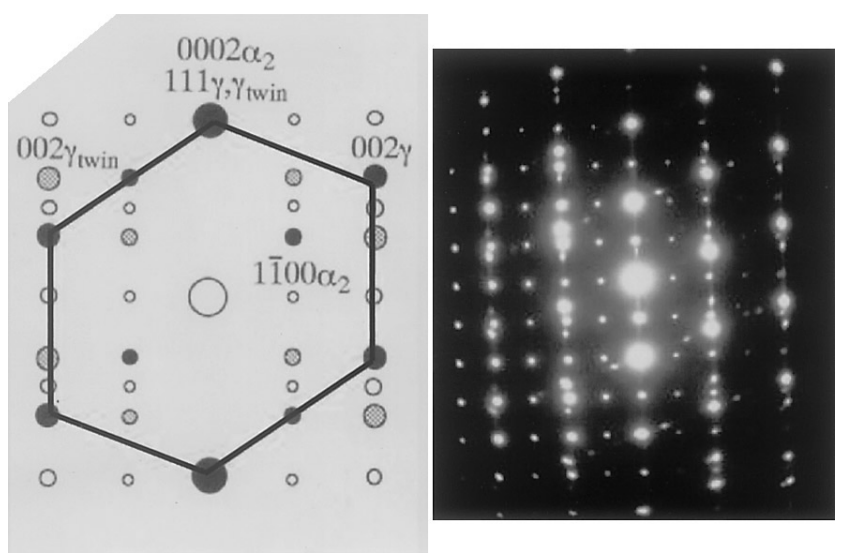

Fig. 10. Diffraction pattern of Fig. 9(a).

(Fig. 8) suggest that the hydrogen environmental embrittlement of TiAl at elevated temperatures was not caused by stable hydride formation.

It is reported that in $\mathrm{V}$ which was cathodically charged with hydrogen, a hydride was formed at a crack tip, i.e. stress concentration region, when the stress was applied to the TEM sample. ${ }^{20)}$ The hydride at the crack tip was unstable, and it disappeared when the stress was removed. This unstable hydride at the crack tip caused the hydrogen embrittlement at room temperature. ${ }^{20)}$ Thus, it is discussed whether a similar formation process of an unstable hydride 


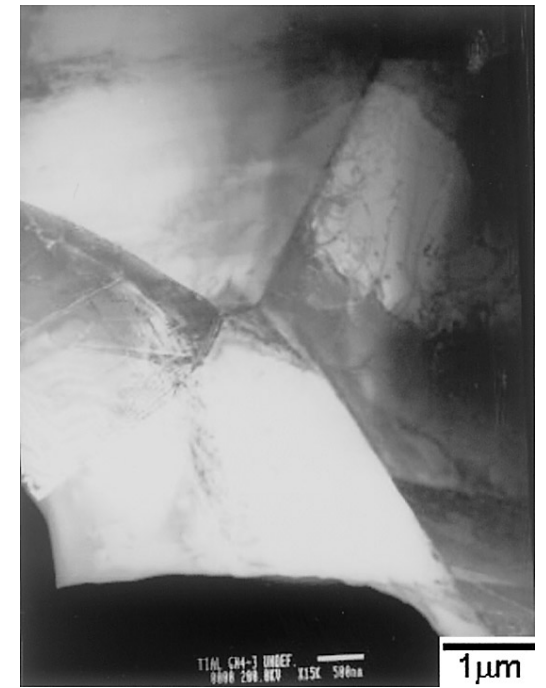

Fig. 11. TEM observation of undeformed part of specimens tested in hydrogen gas at $973 \mathrm{~K}$.

is expected for TiAl.

The diffusion coefficient of hydrogen in a TiAl alloy is reported to be close to that in $\alpha$-Ti at room temperature, ${ }^{21)}$ although it is not measured in a wide temperature range. TiAl and $\alpha$-Ti have fct (the axial ratio, c/a of 1.02) and hcp structures, respectively. Here, the diffusion rate of hydrogen in TiAl is compared with that in $\mathrm{V}$, which has a bcc structure, at $300 \mathrm{~K}$ and $1000 \mathrm{~K}$ using the diffusion data of hydrogen in $\alpha$-Ti and in $\mathrm{V}^{22)}$ Since the pre-exponential factor $D_{0}=0.31 \times 10^{-7} \mathrm{~m}^{2} / \mathrm{s}$ and the activation energy $E_{\mathrm{a}}=0.045$ $\mathrm{eV}$ for the diffusion of hydrogen in $\mathrm{V}$, and $D_{0}=15 \times$ $10^{-7} \mathrm{~m}^{2} / \mathrm{s}$ and $E_{\mathrm{a}}=0.54 \mathrm{eV}$ for that in $\alpha$-Ti, the diffusion coefficients $D\left(=D_{0} \exp \left(-E_{\mathrm{a}} / k T\right), k\right.$ : Boltzmann's constant $)$ of hydrogen are $0.98 \times 10^{-4} \mathrm{~cm}^{2} / \mathrm{s}$ and $1.28 \times 10^{-11} \mathrm{~cm}^{2} / \mathrm{s}$ at $300 \mathrm{~K}$ in $\mathrm{V}$ and $\alpha$-Ti, respectively. That is, the diffusion rate of hydrogen in TiAl is expected to be 7 orders of magnitude smaller than that in $\mathrm{V}$ at room temperature. Thus, the formation and disappearance of an unstable hydride at a stress concentration site like a crack tip is not expected in a short time for $\mathrm{TiAl}$ at room temperature.

The diffusion rate of hydrogen is $0.24 \times 10^{-4} \mathrm{~cm}^{2} / \mathrm{s}$ in $\alpha$ Ti at $1000 \mathrm{~K}$, and it is about $1 / 4$ as large as that in $\mathrm{V}$ at room temperature. From $\mathrm{V}-\mathrm{H}$ and $\mathrm{Ti}-\mathrm{H}$ equilibrium phase diagrams ${ }^{23)}$ the solubility limit of hydrogen in $\mathrm{V}$ is about $2 \mathrm{at} \%(0.04 \mathrm{wt} \%)$ at $300 \mathrm{~K}$, while that in $\alpha$-Ti is about $6 \mathrm{at} \%(0.13 \mathrm{wt} \%)$ at $1000 \mathrm{~K}$, that is, 3 times as large as that in $\mathrm{V}$ at $300 \mathrm{~K}$. Thus, even at $1000 \mathrm{~K}$, the formation and disappearance of an unstable hydride is hardly expected at stress concentration sites like crack tips, dislocations etc. for $\alpha$-Ti.

The above-mentioned discussion on the diffusion coefficient of $\alpha$-Ti suggests that for TiAl the formation and disappearance of an unstable hydride at stress concentration sites are hardly expected in a temperature range of room temperature to $973 \mathrm{~K}$, when the alloy is tensile-tested in a gaseous hydrogen atmosphere. Thus, the hydrogen environmental embrittlement of TiAl is probably caused by the local accumulation of solute hydrogen introduced from the environment even at $973 \mathrm{~K}$, although the total hydrogen content of the specimen is $0.0083 \mathrm{wt} \%$.

\section{Conclusion}

$\mathrm{Ti}-48 \mathrm{Al}-2 \mathrm{Cr}-2 \mathrm{Nb}(\mathrm{at} \%)$ with a $\gamma$ phase structure was tensile-tested in a high purity hydrogen gas in a temperature range of room temperature to $973 \mathrm{~K}$. The reduction of elongation was observed in hydrogen gas in the entire temperature range, although the fracture surface changed mainly from cleavage to grain boundary facets both in vacuum and in hydrogen gas as the temperature increases. The content of hydrogen in the specimens fractured in a hydrogen gas at temperatures of room temperature to $773 \mathrm{~K}$ is hardly different from that in the specimen fractured in vacuum at room temperature. This means that just a little amount of hydrogen permeates into the specimens during tensile testing at these temperatures.

No hydrides were observed by transmission electron microscopy for the specimen fractured in hydrogen gas at $973 \mathrm{~K}$, although the specimen contained $0.0085 \mathrm{wt} \%$ hydrogen. The discussion on the diffusion coefficients of hydrogen in $\alpha$-Ti and $\mathrm{V}$ suggests that the formation and disappearance of a hydride at stress concentration sites like dislocation pile ups and a crack tip are not considered for $\mathrm{TiAl}$, different from $\mathrm{V}$, in which the formation and disappearance of a hydride at a crack tip was reported at room temperature using transmission electron microscopy.

In conclusion, TiAl has been found to exhibit hydrogen environmental embrittlement in a wide temperature range from room temperature to $973 \mathrm{~K}$ in a gaseous hydrogen atmosphere. The hydrogen environmental embrittlement is suggested to result not from the formation of hydrides but from the local accumulation of solute hydrogen introduced by dislocations from the test environment during tensile testing. The hydrogen introduced during deformation mainly reduces not grain boundary strength but cleavage strength, and then the reduction of elongation is caused by the decrease of the transgranular strength in the wide temperature range of room temperature to $973 \mathrm{~K}$, although the grain boundary strength may also decrease with increasing temperature.

\section{Acknowledgements}

This study was supported by Special Coordination Funds for Promoting Science and Technology from the Ministry of Education, Culture, Sports, Science and Technology of Japan, and Visiting Scholar Foundation of Key Laboratory for Environment Sensitive Fracture of the Ministry of Education of P. R. China.

\section{REFERENCES}

1) H. A. Lipsitt, D. Shechtman and R. E. Schafrik: Metall. Trans., 6A (1975), 1991.

2) R. K. Jacobs, A. K. Kuruvilla, T. Nguyentat and P. Cowan: Hydrogen Effects in Materials, ed. by A. W. Thompson and N. R. Moody, TMS, Warrendale, PA, (1996), 331.

3) C. T. Liu: Scr. Metall., 27 (1992), 25.

4) N. Masahashi, T. Takasugi and O. Izumi: Acta Metall., 36 (1988), 1823.

5) T. Takasugi and O. Izumi: Acta Metall., 34 (1986), 607.

6) C. T. Liu and W. C. Oliver: Scr. Metall., 25 (1991), 1933.

7) C. Nishimura and C. T. Liu: Acta Metall., 40 (1992), 723.

8) C. T. Liu, E. H. Lee and C. G. McKamey: Scr. Metall., 23 (1989), 875.

9) C. T. Liu and M. Takeyama: Scr. Metall., 24 (1990), 1583. 
10) M. Nakamura, K. Hashimoto and T. Tsujimoto: J. Mater. Res., 8 (1993), 68.

11) C. T. Liu and Y.-W. Kim: Scr. Metall., 27 (1992), 599.

12) M. Nakamura, N. Itoh, H. Hashimoto, T. Tsujimoto and T. Suzuki: Metall. Mater. Trans. A, 25 (1994), 321.

13) K. W. Gao and M. Nakamura: Mater. Sci. Eng. A, 325 (2002), 66.

14) T. Takasugi and M. Yoshida: J. Mater. Sci., 26 (1991), 3032.

15) M. Takeyama and C. T. Liu: Mater. Sci. Eng. A, 153 (1992), 538.

16) K. Farrell and A. G. Quarrell: J. Iron Steel Inst., 202 (1964), 1002.

17) T. Kawabata, T. Kanai and O. Izumi: Acta Metall., 33 (1985), 1355.
18) M. Nakamura and T. Kumagai: Metall. Mater. Trans. A, 30 (1999), 3089.

19) E. Abe, K. W. Gao and M. Nakamura: Scr. Mater, 42 (2000), 1113.

20) S. Koike and T. Suzuki: Acta Metall., 29 (1981), 553.

21) P. A. Sundaram, E. Wessel, P. J. Ennis, W. J. Quadakkers and L. Singheiser: Scr. Mater, 41 (1999), 75.

22) Y. Fukai, K. Tanaka and H. Uchida: Hydrogen and Metal, Uchidaroukakuho, Tokyo, (1998), 115.

23) Binary Phase Diagrams, 2nd edition plus update CD-ROM, ed. by H. Okamoto, ASM Int., Materials Park, OH, (1996). 